\title{
FER DEL CATALÀ LA LLENGUA PÚBLICA COMUNA
}

\author{
Oriol Amorós \\ Secretari per a la Immigració \\ Jordi Bañeres \\ Responsable d'estudis \\ Secretaria per a la Immigració, Departament d'Acció Social i Ciutadania \\ Generalitat de Catalunya
}

\section{NeCESSiTAT D’UNA LLENGUA COMUNA}

«Com en altres àmbits, l'assentament de població de diferents orígens ha significat canvis en el panorama lingüístic de Catalunya, que, actualment, podríem qualificar de multilingüe, ja que s'hi parlen unes 250 llengües.» ${ }^{1}$. Encara que ben probablement ja estem al voltant de les $300 .{ }^{2}$ D'entre els idiomes de la immigració destaquen pel nombre de parlants el romanès, l'amazic, l'urdú i l'àrab. Aquest multilingüisme no suposa cap problema, sinó que ens incrementa les habilitats relacionals davant la diversitat del món.

No disposem de censos lingüístic ni d'enquestes prou potents per poder estimar fidedignament el volum dels

\footnotetext{
1 Paràgraf 160 Pacte Nacional per a la Immigració. ACORD GOV/231/2008, de 16 de desembre, pel qual s'aprova el Pacte Nacional per a la Immigració.

http://www.gencat.cat/benestar/immi/pdf/docu ment final.pdf. Un pacte per viure junts $i$ juntes: Pacte Nacional per a la Immigració: signat a Barcelona el 19 de desembre de 2008. [Barcelona]: Generalitat de Catalunya, [Departament d'Acció Social i Ciutadania, Secretaria per a la Immigració, 2009]

2 El Centre Internacional Escarré per a les Minories Ètniques i Nacionals i el Grup d'Estudi de Llengües Amenaçades (Universitat de Barcelona) mantenen en permanent actualització la web Les llengües a Catalunya: quantes llengües s'bi parlen?

http://www.ciemen.org/expollengues/index.html
}

idiomes parlats per la immigració a Catalunya.

Davant aquest buit, per aportar, si no unes xifres, sí els ordres de magnitud diacrònics, podem fer servir el criteri de llengua oficial del país d'origen (vegeu gràfic 1). El criteri, doncs, restringeix la informació a una perspectiva molt concreta, que no val a confondre amb la llengua familiar o L1 dels originaris de cada país: que l'àrab sigui l'idioma oficial del Marroc, no significa pas que tots els marroquins siguin arabòfons; ben al contrari, és coneguda la importància de l'amazic dins aquest col lectiu.

Quan un estat és bi- o multilingüe, els contingents humans que en provenen s'han afegit a la rúbrica d'inclassificats.

El model de convivència expressat pel Pacte Nacional per a la Immigració busca un equilibri entre l'objectiu de la cohesió social i el de respectar la diversitat tot aprofitant-ne el potencial. Així doncs, es fa necessari bastir un espai compartit constituit per: (1) una llengua comuna i (2) una cultura pública comuna. La llengua comuna centra tot l'article present, raó per la qual aquí pertoca avançar què entenem per cultura pública comuna. 
Gràfic 1: Percentatge de la població immigrant a Catalunya segons la llengua oficial dels estats d'origen (quan l'estat és oficialment multilingüe es comptabilitza com a inclassificats).

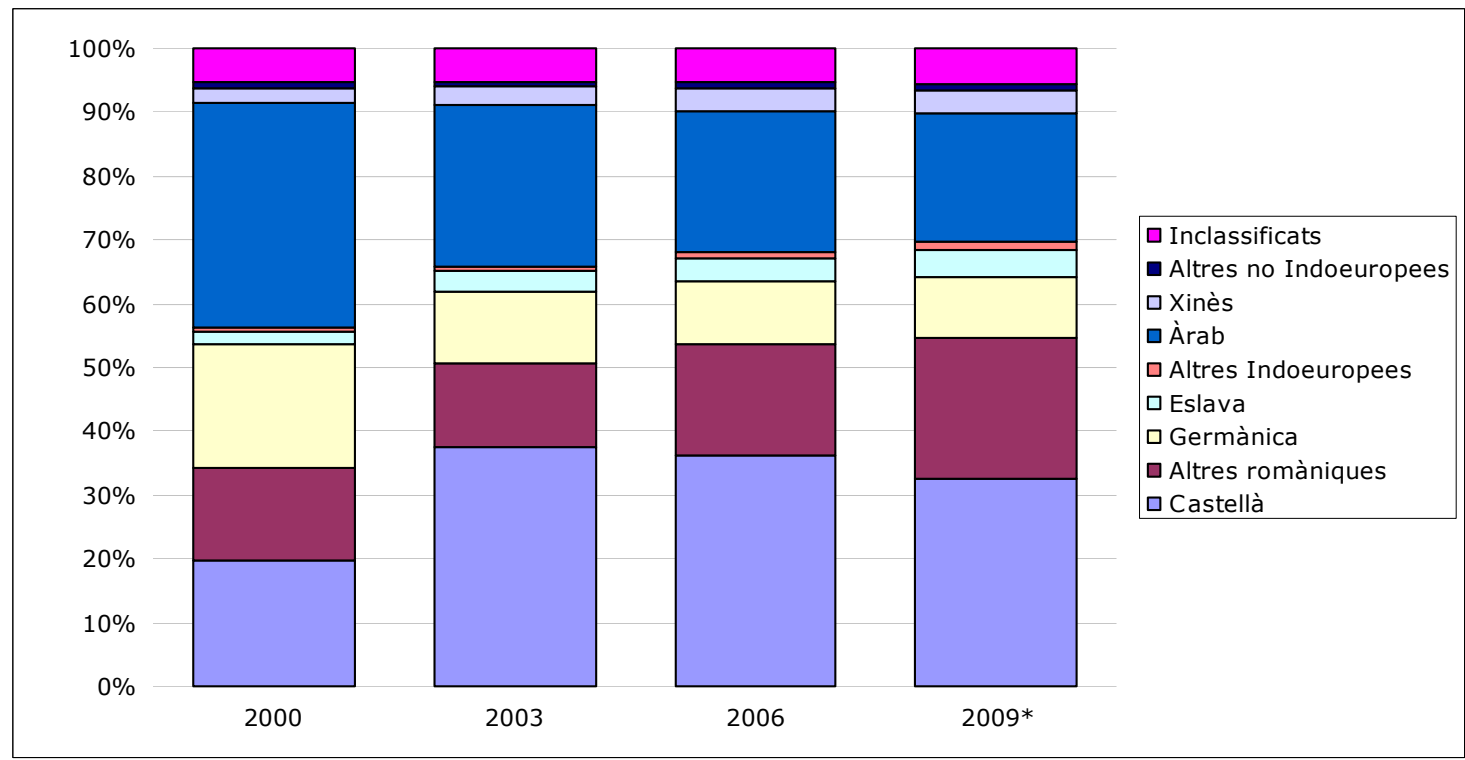

Font: INE. Padrons municipals. Xifres oficials.

* INE. Avenç de padró publicat el 2 de juny de 2009

La cultura pública comuna és un «espai compartit de comunicació, de convivència, e reconeixement i de participació». ${ }^{3}$ Les seves bases són «els valors democràtics als quals aspirem per tradició històrica i política, vinculada al respecte dels drets humans, a la importància concedida a la igualtat i el pluralisme com a principis bàsics d'organització de la societat catalana». ${ }^{4}$ Un element important de les seves bases és «la igualtat entre homes i dones i la inclusió de la perspectiva de gènere en totes les mesures». ${ }^{5}$ En conseqüència és «a favor dels drets humans i dels valors democràtics, l'assistència social, la

\footnotetext{
3 Paràgrafs 25 i 145 del Pacte Nacional per a la Immigració.

4 Paràgraf 146 del Pacte Nacional per a la Immigració. $C f$. també el paràgraf 165 .

5 Paràgraf 172 del Pacte Nacional per a la Immigració.
}

normalització lingüística i la laïcitat». ${ }^{6} \mathrm{La}$ cultura pública comuna ha de permetre la creació d'un sentiment de pertinença que «parteix del reconeixement de les identitats dels països d'origen, socialment compartides, com a premissa de la convivència i la cohesió social». ${ }^{7}$ Per a la seva conformació «caldrà orientar-se, d'una banda, pel principi de reconeixement de la diversitat i, de l'altra, pel principi de redistribució social». ${ }^{8}$ Alhora ha «de fomentar la participació del conjunt de la població jove a les xarxes de participació ciutadana com a via per ser reconeguda i per sentir-se identificada amb la cultura catalana».?

\footnotetext{
6 Política vigent 55 del Pacte Nacional per a la Immigració.

7 Paràgraf 158 del Pacte Nacional per a la Immigració.

8 Paràgraf 150 del Pacte Nacional per a la Immigració.

9 Política vigent 63 del Pacte Nacional per a la Immigració.
} 
La cultura pública comuna inclou un component lingüístic. «La realitat multilingüe de Catalunya és un patrimoni cultural que no es pot menystenir. La cultura pública comuna ha de fomentar la valoració de la linguodiversitat. ${ }^{10} \mathrm{Amb}$ aquesta finalitat, ha de difondre el coneixement sobre les llengües parlades a Catalunya, en sintonia amb el reconeixement que volem del català al panorama lingüístic mundial.». ${ }^{11}$

La valoració de la diversitat, expressió dels usos actuals i potencials, no és possible sense una interfície, sense l'espai compartit que permet la llengua comuna. «Tenint en compte aquesta diversitat, es fa indispensable l'ús d'una llengua que vehiculi la comunicació entre tots els membres de la cultura pública comuna. En aquest sentit, s'ha de potenciar la dimensió cohesionadora que ofereix l'ús públic de la llengua pròpia de Catalunya: el català (i l'occità per a la Val d'Aran).». ${ }^{12}$

Contràriament al que algú ha dit, potenciar el coneixement de la llengua comuna potencia la interculturalitat. La llengua comuna és l'eina imprescindible per vehicular l'hermenèutica necessària per (des)codificar mútuament les cultures, o per dir-ho més planerament, per poder entendre'ns.

El multilingüisme de la diversitat ha de ser vist com un recurs potencial. La gestió de la diversitat suposa ser capaços d'impulsar el reconeixement dels diferents expressions culturals i

10 Linguodiversitat és un concepte encunyat per SkUTNABB-Kangas, Tove. Vide, p. 217 de Linguistic Genocide in Education or Worldwide Diversity and Human Rights. Mahwah, NJ: Lawrence Erlbaum, 2000, p. 276.

11 Paràgraf 164 del Pacte Nacional per a la Immigració.

12 Paràgraf 160 del Pacte Nacional per a la Immigració. lingüístiques i, a la vegada, ser capaços de trobar un espai comú de convivència i de comunicació. Treballar en aquestes dues línies és el repte que tenim com a país.

\section{QUINA LLENGUA COMUNA}

La Catalunya d'avui és multilingüe, oberta i plural i el català hi ha de tenir el paper de llengua comuna. Aquest paper li ve donat per diversos motius.

D’antuvi perquè és la nostra i perquè és la nostra aportació a la diversitat mundial. Des de sempre, la llengua catalana ha tingut la funció d'unirnos. Per això és tan important que avui dia, que formem part d'una societat més heterogènia $i$ diversa que mai, li continuem confiant les funcions de cohesió i inclusió. El català ha generat -i genera- oportunitats (socials, laborals, educatives). El català obre portes, aporta autonomia i genera empaties en la societat d'acollida. El català esborra etiquetes, és un antídot contra l'exclusió.

«[C]ircumstàncies històriques, polítiques i sociolingüístiques fan que, actualment, molts catalans i catalanes optin pel castellà com a llengua de relació amb les persones immigrades». Això impedeix que aquests participin dels entorns que fan ús del català. ${ }^{13} \mathrm{El}$ coneixement del català possibilita la comunicació, genera confiança, expressa voluntat de pertinença i d'acceptació i contribueix a la cohesió social. Per contra, la manca de competències comunicatives dificulta l'autonomia personal i, de retop, la inclusió. ${ }^{14}$

$\mathrm{Si}$ volem que tota la ciutadania, independentment de quin sigui el seu

13 Paràgraf 161 del Pacte Nacional per a la Immigració.

14 Paràgraf 163 del Pacte Nacional per a la Immigració. 
origen, pugui participar en la vida pública $i$ exercir els seus drets en condicions equitatives, cal entendre que la política lingüística és una política social. Té com a objectius ineludibles l'equitat i la justícia, té el compromís de reduir els desequilibris en l'exercici dels drets $i$ ha de garantir a tothom una efectiva igualtat d'oportunitats i un augment del seu benestar.

Això obliga a capacitar lingüísticament en català tots els nouvinguts, fet que requereix un esforç ingent de formació que es vol vehicular, en bona mesura, amb la Llei d'acollida. És un requisit imprescindible perquè puguin participar de manera equitativa en el projecte comú que volem bastir. Per tant, diversitat d'orígens, però unitat de futur en obligacions i en drets (laborals, socials, cívics i polítics) sempre mediats per una comunicació fluïda de tothom amb tothom, és a dir, en una llengua comuna.

El Pacte Nacional per a la Immigració estableix que perquè el català es consolidi «com a llengua d'ús públic i compartida», cal que els diversos agents socials facin un esforç de normalitzacióo. ${ }^{15}$ «L'Administració, per la seva banda, ha de proveir dels recursos necessaris perquè les persones immigrades puguin exercir el seu dret d'accés a l'aprenentatge del català i, a més, ha de fomentar-ne l'ús públic.». ${ }^{16}$

Quin paper, aleshores, per al castellà? D'una banda, «[c]al recordar la importància que tots els nivells d'administració pública [...] respectin el dret d'opció lingüística, també per a les

15 Paràgraf 162 del Pacte Nacional per a la Immigració.

16 Paràgraf 163 del Pacte Nacional per a la Immigració. persones immigrades» ${ }^{17}$ - dret que només cobreix les dues llengües oficials, català i castellà. ${ }^{18}$ D'altra banda, quant als que no són competents en cap de les dues, el Pacte Nacional per a la Immigració «estima que cal oferir recursos per a l'aprenentatge de la llengua castellana a aquelles persones que ho sol licitin i ho requereixin i que ja tinguin adquirides les competències lingüístiques bàsiques en llengua catalana». ${ }^{19}$

El punt és molt important perquè aquí l'ordre de factors altera el producte. Avui, a Catalunya, si hom comença aprenent català, quasi indefectiblement acabarà aprenent castellà; però en l'ordre invers els resultats són molt escassos. Per tant, impulsar el català no causa perjudici al castellà, mentre que potenciar el castellà margina el català.

Aquest principi d'ordinalitat en l'aprenentatge de les llengües oficials per part dels estrangers és anunciat al Pacte Nacional per a la Immigració i establert en forma legal a l'article 9.5 de la Llei d'acollida en termes anàlegs: «Finalitzada la formació de llengua catalana, el servei de primera acollida ha d'oferir la formació per l'adquisició de les competències bàsiques en llengua castellana per aquelles persones que hagin assolit l'adquisició de competències bàsiques en llengua catalana $i$ que ho sol licitin o ho requereixin».

3. LA UTILITAT DE LA LLENGUA COMUNA EN EL PROCÉS D’INTEGRACIÓ

«Els programes d'acollida [dels Estats membres de la Unió Europea]

\footnotetext{
17 Mesura 163 del Pacte Nacional per a la Immigració.

18 Article 33 de l'Estatut d'Autonomia de Catalunya.

19 Paràgraf 163 del Pacte Nacional per a la Immigració.
} 
solen tenir tres components principals: classes de llengua, orientació cívica i formació sobre el mercat laboral.». ${ }^{20}$ Tots els estats —llevat de l'espanyol, excepció ben significativa- carreguen el pes pressupostari de l'acollida en el capítol de la llengua, i és que ensenyar llengua exigeix moltes més hores que no pas l’orientació cívica i la formació sobre el mercat.

A partir d'un acord del Consell Europeu de Tessalònica (juny 2003), la Direcció General de Justícia, Llibertat i Seguretat de la Comissió Europea edita l'any següent, 2004, el Manual sobre integració per a responsables de l'elaboració de politiques $i$ professionals, ${ }^{21}$ que recull un seguit de bones pràctiques d'acollida entre d'altres. El manual explicita que «la formació lingüística constitueix el més important dels esforços d'acollida per als governs. [ ... ] Tot i que els governs assignen molts recursos a la formació lingüística en aquest sentit, el nivell de satisfacció pel que fa a l'assoliment de resultats no és gaire alt.». ${ }^{22}$

En la mateixa direcció és imprescindible referir-se al quart dels anomenats Principis Bàsics Comuns de la Política d'Integració d'Immigrants de la Unió Europea, aprovats pel Consell de Ministres de Justícia i Afers d'Interior de la UE el 19 de novembre de 2004, i assumits pel Consell Europeu de 16 i 17 de desembre del mateix any. Aquest principi afirma: «Des connaissances de base sur la langue, l'histoire et les

20 Departament d'Acció Social i Ciutadania. Projecte de Llei d'Acollida de les persones immigrades i les retornades a Catalunya. [Barcelona: Departament d'Acció Social i Ciutadania], 2 de juny de 2009, 25. Vide p. 4 del Preàmbul del III. L'acollida, en el marc de la política europea.

21 Luxemburg: Direcció General de Justícia, Llibertat i Seguretat, 2004, p. 84.

22 Ibídem, p. 15 ss. institutions de la société d'accueil sont indispensables à l'intégration.». ${ }^{23}$

La mateixa comissió ho revalidava l'any següent, el 2005: «Basic knowledge of the host society's language, history, and institutions is indispensable to integration; enabling immigrants to acquire this basic knowledge is essential to successful integration.». ${ }^{24} \mathrm{I}$ ho reblava dos anys després, el 2007: «Les compétences linguistiques sont essentielles à l'intégration. Les migrants peuvent être pris dans un cercle vicieux qui fait que l'accès au marché du travail leur est barré faute de connaissances linguistiques suffisantes alors que c'est l'emploi et la formation qui permettent de développer ces connaissances. L'acquisition de la langue du pays d'accueil peut revêtir un importance particulière pour les femmes migrantes, qui risquent sinon de se voir coupées de leur nouvel environnement et d'avoir des difficultés à aider leurs enfants à s'intégrer à l'école.». ${ }^{25}$

Segons un estudi economètric dirigit pel Dr. López Casasnovas i col laboradors $(2009)^{26}$, el coneixement

23 Commission ses Communautés Européennes. Vers une politique commune en matière d'immigration Bruxelles, le 5.12.2007. COM(2007) 780 final

${ }^{24}$ Commission Of The European Communities. Brussels, 1.9.2005. $\operatorname{COM}(2005) 389$ final. Communication from the Commission to the Council, the European Parliament, the European Economic and Social Committee and the Committee of the Regions. A Common Agenda for Integration Framework for the Integration of Third-Country Nationals in the European Union

25 Communication de la Commission au Parlement européen, au Conseil, Comité économique et social européen et au Comité des régions - Vers une politique commune en matière d'immigration \{SEC(2007) 1632\} /* $\mathrm{COM} / 2007 / 0780$ final */

26 LÓPEZ CASASNOVAS, Guillem (Dir.); FERRAGUT, Gabriel; MOSTERÍN, Ana; NICODEMO, Catia (Investigadors) "Efectes econòmics de les politiques d'integració dels immigrants" Paradigmes, 2, juliol 2009, http://www.gencat.cat/diue/doc/doc 10017442 
del castellà a Catalunya aporta beneficis econòmics. Del cost net resultant (beneficis socials, quan considerem els efectes agregats sobre la societat, o ingressos fiscals addicionals, quan l'anàlisi es limita als resultats del sector públic, menys el cost d'implementar el programa perquè els immigrats aprenguin el castellà una part es quantifica com a guanys directes, monetaritzats en el mercat de treball i apropiats per part dels usuaris del programa que es troben en condicions d'obtenir aquesta prima, associada a llur major productivitat. Resta aquí configurar el que podria suposar, com a prima addicional, el coneixement del català, per sobre de la del castellà: té una valoració social observable però de mal quantificar en termes econòmics. A tall d'il lustració, si consideréssim un plus del 10\% sobre les primes abans computades, aquest tant per cent suposaria un increment de beneficis que, en cadascun dels tres escenaris que l'equip del Dr. López Casasnovas hipotitza, elevaria la part corresponent a la prima lingüística a l'entorn del 5\% (segons el pes de l'efecte lingüístic sobre els beneficis totals). ${ }^{27}$

A aquestes valoracions, caldria afegir-hi els beneficis globals concurrents per al conjunt de la comunitat. Així, els beneficis indirectes que rebrien els ascendents $i$ descendents dels usuaris del programa, en forma d'un millor benestar (per als subjectes actius millors ocupacions laborals i més ben retribuïdes que el que redunda per als subjectes passius en millor qualitat de vida: capital

1.pdf. Nosaltres fem ús de la seva versió prèvia, més extensa, però inèdita, Avaluació dels costos $i$ beneficis econòmics associats al programa proposat per la Secretaria per a la Immigració del Departament d'Acció Social $i$ Ciutadana de la Generalitat de Catalunya per a la millora del coneixement del país d'acollida per part dels immigrants. Barcelona: s.e., 2008, p. 81.

${ }^{27}$ p. 56. LÓPEZ CASASNOVAS, op. cit. humà i educació per als nens, menys exclusió de les persones grans, etc.). Més encara, també beneficia la resta de la societat en incrementar el capital social, reduir la precarietat, la necessitat d'actuacions públiques i privades en situacions d'emergència social, etc. Només que aquests factors rebessin un valor «ombra» equivalent al 145\% del que suposa la resta de beneficis en un primer moment (però que minvaria força en els anys successius fins a situar-se entorn del $40 \%$ a partir del quart període), el programa ja assoliria valors nets positius ben palesos. ${ }^{28}$

De fet, cap novetat, els beneficis que per als immigrants comporta dominar la llengua del país han estat estudiats a bastament: per l'anglès als Estats Units; ${ }^{29}$ pel francès $i$ anglès al Canadà; $;^{30}$ per l'hebreu a Israel ${ }^{31}$, etc. ${ }^{32}$ I

${ }^{28}$ p. 57. LÓPEZ CASASNOVAS, op. cit.

29 CHISwICK, Barry R.; Miller, Paul W. Matching Language Proficiency to Occupation: The Effect on Immigrants' Earnings. Forschungsinstitut zur Zukunft der Arbeit $=$ Institute for the Study of Labor

(Discussion paper series) IZA DP No. 2587. January 2007.

30 WARMAN, Casey. «Ethnic enclaves and immigrant earnings growth» Canadian Economics Association, Canadian Journal of Economics, 40, 2, May 2007: 401-422. CHISwICK, Barry ; MILLER, Paul W. The complementarity of language and other buman capital: Immigrant earnings in Canada. Vancouver Centre of Excellence: Research on Immigration and Integration in the Metropolis (Working Paper Series \#00-08) July 2000 CHIswick, Barry R.; Miller, Paul W A Model of Destination Language Acquisition: Application to Male Immigrants in Canada. Vancouver Centre of Excellence: Research on Immigration and Integration in the Metropolis. (Working Paper Series. \#00-13). September 2000. 52 p.

31 CHISWICK, Barry R; REPETTO, Gaston. Immigrant Adjustment in Israel: Literacy and Fluency in Hebrew and Earnings. Discussion Paper No. 177. July 2000.

32 Com mostren les tres notes anteriors, B.R. CHISWICK és un autor més destacat en l'econometria de les llengües. Com a comparació 
els resultats sempre són positius i prou comparables entre ells.

\section{Polítidues Per al Foment de la LLENGUA CATALANA}

\subsection{Pacte Nacional per a la Immigració}

Des de la Secretaria per a la Immigració [SIM] hem impulsat que els actors socials del país, incloent-hi les administracions, es comprometin en un conjunt de mesures per a governar el fet migratori i garantir la cohesió social en una triple dimensió que s'expressa en tres eixos: gestionant el flux migratori des de la legalitat i d'acord amb el mercat de treball (eix 1); adaptant els serveis públics a la nova demografia (eix 2) i treballant per a la integració en una cultura pública comuna (eix 3). Compromet, en conseqüència, a fer del català la llengua pública comuna. Així ho explicita l'eix 3, repte 2 del Pacte Nacional per a la Immigració, que concreta en la mesura 47:

«Fomentar la pràctica del català com a llengua pública comuna pels diversos actors socials del país, facilitant l'apropiació del català per a totes les persones.

1. Assegurar que tots els membres de la societat catalana tinguin la possibilitat d'adquirir[-ne] competències lingǘstiques bàsiques [...].

2. Garantir [...] els recursos per a l'ensenyament del català als nous catalans i catalanes [...]

4. Donar suport governamental a les iniciatives ciutadanes d'aprenentatge $\mathrm{i}$ ús del català $[\ldots]$

general, vegeu Barry CHISWICK; Michael E. HuRsT. The Employment, Unemployment and Unemployment Compensation Benefits of Immigrants. Discussion Paper No 129. March 2000.
5. Utilitzar preferentment el català per part de les administracions i els mitjans de comunicació públics de Catalunya. $[\ldots] \gg$

Aquest acord ha estat elaborat amb l'objectiu de donar resposta a les demandes de la ciutadania respecte al fet migratori i, a l'ensems, compromet el conjunt d'actors signants. Per assolir-lo, es va partir d'un procés previ de recollida d'antecedents mitjançant l'entrevista a 80 experts locals, un procés de redacció per part de quatre equips d'experts (unes 40 persones en total), un primer procés de negociació entre els agents signants, un procés participatiu en el qual més de 1.500 persones (la majoria provinents de les àrees d'immigració dels municipis i de les entitats relacionades amb la immigració) feren un total de 2.000 aportacions i, finalment, un procés de negociació definitiu a cinc nivells: entre els diferents departaments del govern, amb les entitats municipalistes, amb els agents econòmics $i$ socials, amb les entitats de la Taula de Ciutadania i Immigració i amb els partits polítics, dels quals signaren finalment l'acord ERC, PSC, ICV i CiU, representant el 90\% del Parlament de Catalunya.

És, per tant, el primer acord polític i social que compromet la societat catalana, de forma abastament representada, amb la voluntat de fer del català la nostra llengua comuna.

\subsection{Llei d'acollida}

Com a conseqüència del Pacte Nacional per a la Immigració, el govern ha impulsat la Llei d'acollida de les persones immigrades $i$ les retornades a Catalunya, aprovada al Parlament el 28 d'abril de 2010, primer text legal que 
reconeix el paper de llengua comuna per al català.

L'oportunitat de la llei s'explica a partir de tres fets. El primer és que les persones immigrades que coneixen la llengua catalana, el mercat laboral i la societat d'acollida guanyen autonomia personal, milloren les rendes i són menys dependents. En segon lloc, no es pot obviar que el canvi demogràfic viscut té un fort impacte en el conjunt de la societat i es fa necessària, per tant, una gran actuació de formació per a l'apropament entre les persones nouvingudes i la societat catalana. I, finalment, cal tenir en compte que l'arribada és un dels moments clau: la primera imatge, el primer contacte i les primeres relacions que una persona rep de la societat que l'acull la condicionen en la visió que pren del lloc on ha arribat i en la plena incorporació social al país.

La llei defineix els instruments per a l'acollida de les persones nouvingudes, els continguts formatius del servei d'acollida; estableix el marc competencial dels ens locals i de la Generalitat de Catalunya; dóna forma a la col laboració institucional en polítiques d'immigració, i crea l'Agència de les Migracions de Catalunya.

Dins l'apartat més significatiu de la llei, el de la creació del servei universal d'acollida, hi figuren accions formatives en tres àmbits (veure gràfic adjunt): llengua, coneixement del mercat laboral i de la societat d'acollida.

Aquesta formació donarà lloc a una acreditació que, si bé no és en cap cas preceptiva, tindrà utilitat tant per al reconeixement en el mercat laboral com per als diferents tràmits regulats en la legislació (estatal) d'estrangeria, on és requerit provar un esforc d'integració. Es desenvolupa, així, la competència reconeguda a les comunitats autònomes d'emetre informes d'integració en la darrera reforma de la llei d'estrangeria per als tràmits d'arrelament, renovació de les autoritzacions de residència temporal $\mathrm{i}$ accés a la nacionalitat. Aquest és, sens dubte, un dels principals arguments que ens permeten afirmar la importància d'aquesta llei i el canvi que suposa.

Pel que fa al rol del català en la formació lingüística que es preveu, una simple lectura del seu article 9 permet veure que és perfectament coherent amb allò que s'ha dit prèviament $\mathrm{i}$ que es va acordar al Pacte Nacional per a la Immigració.

1. Al llarg del seu procés d'integració a la societat catalana, la persona titular del dret d'accés al servei de primera acollida ha d'assolir les competències lingüístiques bàsiques en català i en castellà.

2. El servei de primera acollida ha d'oferir la formació i els mitjans necessaris per a l'adquisició de les competències bàsiques en llengua catalana a les persones titulars del dret d'accés al servei que no la coneguin, sempre que sigui possible mitjançant el Consorci per a la Normalització Lingüística.

3. Reglamentàriament es fixarà el nivell de referència mínim a assolir quant a les competències lingüístiques referides en el marc europeu comú de referència per a les llengües, establert pel Consell d'Europa.

4. En la seva condició de llengua pròpia de Catalunya, el català té la consideració de llengua comuna per a la gestió de les polítiques d'acollida i d'integració. Té també la consideració de llengua vehicular de la formació i la informació, instrument bàsic per a la plena integració al país. Amb aquesta finalitat, l’aprenentatge lingüístic ofert 
pels serveis de primera acollida començarà per l'adquisició de les competències bàsiques en llengua catalana.

5. Finalitzada la formació de llengua catalana, el servei de primera acollida ha d'oferir la formació per adquirir les competències bàsiques en llengua castellana a aquelles persones que hagin assolit l'adquisició de competències bàsiques en llengua catalana $\mathrm{i}$ que ho sol licitin o ho requereixin.

\section{Itinerari dels serveis de primera acollida}

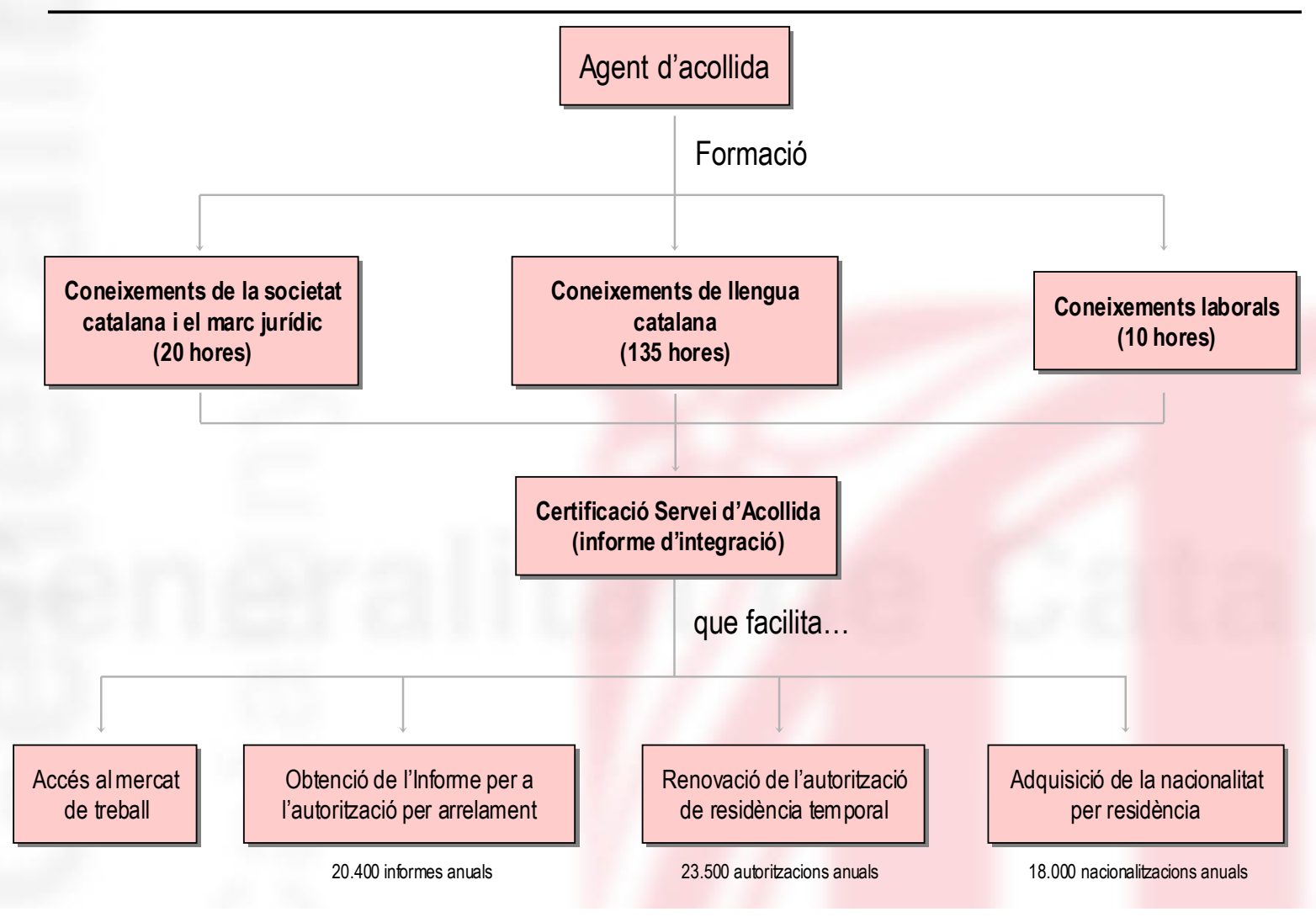

\subsection{Cursos d'acollida}

En aquest marc s'adiu esmentar que en el cursos d'acolliment lingüístic (català inicial i bàsic) de l'exercici 200708, impartits pel Consorci per a la Normalització Lingüística, el nombre d'estrangers matriculats respecte a l'exercici anterior s'incrementà en un $27 \%$. En l'exercici següent, l'augment ha estat del $14 \%$, de manera que l'alumnat estranger ascendeix a $66.612(84,1 \%$ del total). La meitat prové d'Amèrica Llatina, però es detecta la incorporació creixent d'estudiants d'Àsia (més que més de Pakistan i la Xina), Àfrica (sobretot el Marroc) i Romania.

Per contribuir a aquest esforç ingent, de 2005 ençà, la Secretaria per a la Immigració finança íntegrament els cursos d'iniciació al català que impulsen les entitats d'immigrants i que tenen lloc 
en llurs seus socials. En els municipis grans, les entitats han de poder garantir, pel cap baix, 20 alumnes. En els municipis petits de fora de l'àmbit metropolità, l'ajuntament o el consell comarcal són els que actuen davant de la Secretaria per a la Immigració en representació de les entitats interessades, i la xifra d'alumnes mínima pot arribar a ser inferior. Mitjançant aquestes vies, en el curs 2008-09 s'impartiren 356 classes, que arribaren a un total de 7.255 alumnes, la qual cosa equival a una mitjana de 20,4 alumnes per classe. En tots els caos es tracta d'una oferta de formació gratuïta i en horaris adaptats a les necessitats dels alumnes. Significa, doncs, una complementació de l'oferta habitual del Consorci per a la Normalització Lingüística, que imparteix sempre les classes en les seves aules.

\subsection{Reforc educatiu per a nens i nenes vinguts per reagrupament familiar}

La Secretaria per a la Immigració juntament amb disset ajuntaments i dos consells comarcals han creat els mitjans per poder ensenyar català durant les vacances d'estiu a l'alumnat arribat a casa nostra entre setembre 2008 i juny de 2009. En el marc d'activitats de lleure, com ara els casals municipals, s'oferiren 100 hores d'aprenentatge de la llengua a més de 750 infants (d'un total de 2.200 menors reagrupats que arribaren en els primers sis mesos del 2009), combinades amb accions de coneixement de l'entorn $\mathrm{i}$ interrelació amb altres alumnes. Atesa la reeixida, hom treballa perquè a partir de l'estiu de 2010 aquesta proposta beneficii el $100 \%$ del nou alumnat que vagi arribant al país.

\subsection{Projectes amb entitats}

En el capítol de projectes amb entitats, la SIM té establerts una cinquantena de convenis de col laboració, així com una convocatòria de subvencions a projectes per a la integració a partir de la qual s'estableixen col laboracions amb prop de 300 entitats. De tots aquests projectes voldríem destacar les col laboracions amb Òmnium Cultural i el programa Quedem?, amb la Coordinadora d'Associacions per la Llengua i el grup de cnversa Xerrem, i amb la Plataforma per la Llengua.

Quedem? ?33, sota la responsabilitat d'Òmnium Cultural, aporta continuïtat al Voluntariat per la Llengua. Mentre el voluntariat lingüístic consisteix en una trobada d'una hora setmanal entre un catalanoparlant i un nouvingut per practicar el català, el Quedem? proposa un seguit de sortides en colla que pretenen promoure la cohesió social entre tots els ciutadans, independentment de llur procedència.

Xerrem, sota la responsabilitat de la Coordinadora d'Associacions per la Llengua, consisteix en grups de conversa per parlar en català amb fluïdesa $i$ seguretat, basat en criteris de proximitat ${ }^{34}$ (recorda el programa de voluntariat per la llengua, però amb un plantejament grupal, sumat a una certa estructuració de les activitats).

Plataforma per la Llengua. La Secretaria per a la Immigració ha col laborat en:

1. Organitzar una acte públic per a la sensibilització durant la Diada de Sant Jordi amb el lema El català, llengua comuna,

\footnotetext{
${ }^{33}$ Quedem?

http://quedem.omnium.cat/www/quedem/ca/

34 ESTEBAN, Jordi. «Xerrem, una iniciativa de

voluntariat per fomentar l'ús social del català»,

Llengua i Ús 2009, 44: 44-54.
} 
que inclou tasques prèvies de difusió, estands d'entitats de persones immigrades que difonen el català; diferents mostres de la cultura dels països d'origen en la seva llengua pròpia i en català.

2. L'edició del DVD Tota arrel : el català, llengua comuna. L'edició de 5.000 DVD amb un espectacle de fusió creat específicament per a la Diada en què hi han col laborat intèrprets i grups musicals de la societat d'acollida amb d'altres vinculats als col lectius de nouvinguts.

3. Dinamització lingüística d'entitats i organitzacions de la immigració. La xarxa d'entitats i organitzacions de la immigració de la Plataforma per la Llengua està integrada per 23 entitats de persones immigrades. L'objectiu d'aquesta xarxa és incentivar les relacions interculturals i treballar iniciatives conjuntament en pro del català. La dinamització inclou: (1) visites periòdiques a les seus socials de les entitats, (2) organització de les reunions mensuals, (3) participació i suport a les iniciatives de les entitats i difusió de llurs activitats a través dels mitjans que disposa la Plataforma per la Llengua, (4)generació d'idees $\mathrm{i}$ projectes en consonància $\mathrm{amb}$ els objectius de la xarxa, (5) ajut i suport a les entitats perquè puguin trametre als responsables polítics i socials llurs problemàtiques i inquietuds.

\subsection{Materials d'aprenentatge}

La Secretaria per a la Immigració també contribueix a l'edició de materials per a l'aprenentatge de la llengua. La col lecció Viure en català: aprenem català des de... consisteix en materials elaborats i editats conjuntament amb la Secretaria de Política Lingüística (Departament de la Vicepresidència), que proporcionen un primer contacte amb la llengua catalana, alhora que permeten entendre i practicar frases quotidianes, bo $\mathrm{i}$ facilitant les comunicacions amb la societat d'acollida.

Els materials estan dividits en tres apartats:

(1) Informació bàsica de la llengua i societat catalanes i sobre la llengua catalana vista des d'un determinat idioma estranger.

(2) L'apartat Materials per a l'acolliment lingü̈stic: aprenem català conté deu lliçons de català inicial que tracten de temes relacionats amb la vida quotidiana; cada lliçó inclou diàlegs breus i un vocabulari relacionat amb el tema.

(3) L'apartat Comencem a parlar conté també diàlegs relacionats amb la vida quotidiana, però amb més aprofundiment.

Per ara n'hem publicat les versions xinesa, àrab i romanesa, i estan en preparació les edicions en amazic i urdú.

\subsection{Edició del suplement 'Vivim Junts'}

Vivim Junts és una publicació de la Secretaria per a la Immigració que s'encarta un cop al mes en diverses publicacions periòdiques en paper adreçades a un públic immigrat que viu a Catalunya.

Taula 1: Publicacions immigrants de Catalunya que encarten el suplement "Vivim Junts".

\begin{tabular}{|l|l|}
\hline Latino & 30.000 \\
\hline Toumai & 25.000 \\
\hline Revista Mà Osona & 9.000 \\
\hline Revista Mà Camp de Tarragona & 9.000 \\
\hline Catalina & 12.000 \\
\hline ARG Express & 7.000 \\
\hline Sí se puede & 30.000 \\
\hline
\end{tabular}

Vol ser una eina per a l'autoaprenentatge de la llengua catalana a 
través de la lectura de notícies relacionades amb serveis públics i actuacions d'interès per a la immigració. Per això al final dels articles hi ha un breu glossari que tradueix algunes paraules i les fitxes Aprendre català, elaborades per la Secretaria de Política Lingüística.

\subsection{Projecte pilot d'alfabetització en català}

El projecte pilot, engegat el darrer quadrimestre de l'any 2009, ha tingut com a finalitat alfabetitzar les persones estrangeres per incrementar-ne l'autonomia personal i servir de model per a la consecució de l'èxit escolar dels seus fills. Es van fer 76 cursos vinculats a les escoles dels fills i filles dels alumnes, de 40 hores de duració i amb derivació final a les escoles d'adults, a 66 municipis, i s'hi van inscriure 1.037 alumnes, dels quals 736 van finalitzar el curs. Entre aquests darrers alumnes, la nacionalitat més nombrosa és la marroquina (391), la llengua familiar més parlada, l'amazic (272) i majoritàriament són dones (507).

\subsection{Altres programes}

Finalment, per manca d'espai, esmentarem, just a títol d'inventari, diverses accions en pro de la llengua, en què la Secretaria per a la Immigració participa en diversos aspectes: curs bàsic per a agents d'acollida, tallers d'ús de la llengua com a via d'igualtat d'oportunitats per a funcionaris públics, formació en llengua catalana adreçada a entitats; formació en llengua catalana adreçada a professionals de la restauració, l'hoteleria i el petit comerç, en col laboració amb el Departament d'Innovació, Universitats i Empresa (programa PROFIT).

\section{MultilingÜISME}

La Secretaria per a la Immigració treballa per compatibilitzar dos objectius igualment irrenunciables:

(1) Que el català esdevingui la llengua comuna i de cohesió social, compartida per tota la ciutadania.

(2) Que qualsevol ciutadà, independentment de la seva competència idiomàtica, pugui participar en la vida pública i exercir els drets en les condicions més equitatives possibles. Dit altrament, per garantir l'accés als serveis públics vitals, cal garantir l'ús instrumental dels idiomes de la nova ciutadania que ignora les llengües oficials de Catalunya, alhora que cal pressionarlos perquè les aprenguin. Aquest objectiu és assumit per la immensa majoria de la població, perquè a diferència del que s'esdevé en societats monolingües, la ciutadania catalana comparteix el reconeixement i el valor de la diversitat.

Advenir una societat multilingüe, amb subjectes plurilingües, ens proporciona un avantatge comparatiu. Ens connecta amb el món: tot el món, amb implicacions culturals i econòmiques.

Culturals: ja no necessitarem que les relacions entre cultures siguin mitjançades per les grans llengües mundialitzadores, amb la distorsió consegüent que això comporta. Catalunya pot esdevenir un centre d'intercanvi de coneixements, d'arts i ciències (com ho era l'escriptori de Ripoll mil any enrere).

Econòmiques: amb l'anglès hom es pot comunicar amb les elits d'arreu, però no n'hi ha prou quan es tracta d'afinar (per exemple, en abordar qüestions jurídiques), quan s'ha d'enraonar amb interlocutors de nivell mitjà (per exemple, des d'un funcionari 
local a un capatàs d'obra) o quan la comunicació gira entorn de la idiosincràsia local (per exemple, quan es parla de les connotacions subliminars dels hàbits de consum). La diversitat lingüística interpel la no sols els professionals de la traducció i interpretació, i els de l'àmbit de les migracions. També genera oportunitats en la tecnologia de la veu, de l'edició, etc. alhora que es vincula a la creació de novells esports, formes de comerç, etc.

\section{Pacte Nacional per a la} Immigració. El paràgraf 48 preveu «Difondre el coneixement de la diversitat lingüística com a patrimoni de Catalunya.

1. Afavorir l'ensenyament de les llengües dels països d'origen de la població en horari extraescolar.

2. Afavorir el reconeixement de la diversitat lingüística dels països d'origen, amb especial atenció a aquelles llengües utilitzades per les persones immigrades residents a Catalunya que han patit algun tipus de discriminació en els seus països d'origen.».

Haver-nos transmutat en un país multilingüe suposa també una avinentesa per donar valor a parles discriminades en llur país d'origen. Aquest és el cas, per exemple, del romaní i de l'amazic. Pel romaní és vigent el Pla Integral del Poble Gitano 2009-2013 ${ }^{35}$ amb l'objectiu de combatre la situació de desigualtat que pateix la població rom, promocionant-ne els trets propis, incloent-hi la recuperació

35 Acord de Govern. 30.06.2009. Pla Integral del Poble Gitano a Catalunya 2009-2013 =

Plan Integral del Pueblo Gitano en Cataluña 2009-2013 = Integràlo plàn e rromani selâqo and-i Katalònia 2009. 2013 = Integrated Plan for the Roma People in Catalonia 2009-2013. [Barcelona]: Generalitat de Catalunya, Departament de Governació i Administracions Públiques, Secretaria d'Acció Ciutadana [2009] p. 340. Interessen les p. 48, 54, 57 i 64. de la seva llengua. Quant a l'amazic, ${ }^{36} \mathrm{el}$ Pla de Ciutadania i Immigració 2005$2008,^{37}$ responsabilitat directa de la Secretaria, impulsà l'ensenyament en horari no lectiu de la llengua i la cultura amazigues.

Projecte de Llei d'acollida de les persones immigrades $\mathrm{i}$ les retornades a Catalunya. Article 12

«Altres aspectes del servei [de Primera Acollida]:

4. En relació a[mb] les llengües pròpies de les persones usuàries del servei, sempre que sigui necessari, es pot:

- Emprar-les en les activitats formatives $\mathrm{i}$ informatives, d'acord amb les recomanacions i protocols tècnics elaborats $\mathrm{amb}$ aquesta finalitat.

- Incorporar-les als materials, a més del català.».

\section{EDICIÓ DE MATERIALS DIVERSOS}

- Edició de la col lecció Llengua, immigració $i$ ensenyament del català per facilitar l'ensenyament del català als parlants d'altres idiomes concrets. Entre 2002-2005 s'han editat, consecutivament, l'àrab, el xinès, el soninké i el mandinga, el berber [sic], el ful i el wòlof, el panjabi, el romanès, l'ucraïnès i el tagal.

- Edició d'enregistrament de vídeo de Suport a l'acollida en sis DVD (2008), adreçat als professionals de l'acollida a les persones nouvingudes. Presenta Catalunya i la societat catalana i endemés

36 Tilmatine, Mohmand. «La immigració amaziga a Catalunya: l'aposta identitària i ciutadana». Llengua $i$ Ús, 34. Tercer quadrimestre 200547, 2007: 353-383.

37 Pla de Ciutadania i Immigració 2005-2008. [Barcelona]: Generalitat de Catalunya, Departament de Benestar i Família, Secretaria per a la Immigració, [2005]. p.196. Interessa la p.144; ARENY I CIRILO, M. Dolors «L'acomodació de la població escolar amazigòfona a Catalunya». Revista de Llengua i Dret, 47, 2007: 353-385. 
aporta informació pràctica sobre l'organització, l'accés, les característiques i els drets i deures dels usuaris dels serveis públics. El videodiscs estan dedicats a Catalunya: treball,; habitatge i convivència, salut, educació, i serveis socials. El seu àudio està disponible en català, castellà, anglès, francès, àrab, amazic, xinès, urdú, romanès i rus.

- Guia d'acollida (2009): web adreçada a qui pensa a venir o ja és aquí de fa poc. La web també està traduïda als deu idiomes més parlats. La quarta edició dels premis European eGovernment Awards, apadrinats per la Comissió Europea, dedicats a les millors pràctiques i a les solucions electròniques més novadores de les administracions públiques de la UE ha reconegut l'estratègia multicanal d'atenció ciutadana que la Generalitat ha desenvolupat en aquesta $\mathrm{i}$ en d'altres webs. ${ }^{38}$

- Elaboració i difusió de material multilingüe (políptics, opuscles, fullets, etc.). Pot servir d'exemple per tot aquest material El català, llengua d'acollida (2008), tríptic de sensibilització escrit en set idiomes.

La convocatòria de subvencions i contractes-programa del Departament d'Acció Social i Ciutadania amb els ens locals, per tal de desenvolupar programes i accions d'acollida i d'integració, ha prestat suport econòmic als serveis de traducció, interpretació i mediació dels ens locals. En el 2008 i 2009, respectivament, va beneficiar 49 i 47 projectes de traducció i interpretació, i 47

38 Citizen-Care-Centric: eGovernment in Catalonia. Barcelona: Presidential Department, Deputy Secretariat General, Directorate General of Citizen Attention, 2009. p.194. i 46 contractacions de mediadors interculturals. $^{39}$

Suport a programes $\mathrm{i}$ activitats d'entitats diverses. El 2007 es va ajudar la comunitat islàmica de Martorell per fer cursos d'àrab als infants.

El 2008 es va ajudar l'Associació Motivadora d'Integració i Convivència AMIC Amazigh (Vic) per fer cursos d'àrab i amazic; a Som Dones (Taradell) per muntar un taller de dones que oferien classes d'àrab per als infants; a l'Associació per a la Multiculturalitat, la Informació i la Convivència Social (Badalona) pel projecte Ara Menors Àrab (activitats en àrab entre menors arabòfons).

El 2009 es va ajudar a l'Asociación Cultural Ibne Sinaa (Les Franqueses del Vallès) per fer cursos de formació en llengua àrab; a l'Associació per a la Multiculturalitat, la Informació i la Convivència Social (Badalona) pel projecte Ara Menors Àrab; a l'Associació Cultural dels Drets del Poble Amazigh a Catalunya (Figueres) per activitats per propulsar el coneixement de la cultura catalana i de la cultura amaziga a tota la ciutadania.

Suport a l'exposició «Les llengües a Catalunya» del Grup d'Estudi de Llengües Amenaçades. ${ }^{40}$ Es tracta d'una exposició itinerant, muntada el 2005, i que d'aleshores ençà circula sobretot per escoles i centres cívics.

\footnotetext{
39 Cf. Departament d'Acció Social i Ciutadania. Memòria del Departament d'Acció Social i Ciutadania: 2007. Barcelona: Generalitat de Catalunya, Departament d'Acció Social i Ciutadania, 2000. p. 280.

40 ACEDO, Víctor, Gras, Pedro, Les paraules viatgen: Catàleg de l'exposició Les llengües a Catalunya: Quantes llengües s'bi parlen? Barcelona: Universitat de Barcelona, Departament de Lingüística General de la UB, Octaedro. 2005. Literatura grisa.
} 
Formació de professionals de la immigració, a través de l'oferta formativa de la Secretaria per a la Immigració, i que es pot exemplificar amb les cinc edicions al llarg de l'exercici 2008-2009, del curs «La pluralitat lingüística de la immigració present a Catalunya», que és de 30 hores i organitzat amb la col laboració de Linguamón - Casa de les Llengües. ${ }^{41}$

\section{CLOENDA}

Des de la Secretaria per a la Immigració maldem per establir un marc de respecte, coneixement i divulgació de les llengües i cultures que aporta la nova immigració, en consonància amb el tradicional compromís de la societat catalana vers la diversitat i la pluralitat.

Els serveis de gestió del pluralisme lingüístic han de tenir un caràcter temporal i just durant el procés d'acollida, etapa en què cal insistir en la necessitat de l'aprenentatge del català perquè hom assoleixi les mateixes oportunitats que la resta de ciutadans, per ser més autònom $\mathrm{i}$ per entendre i comprendre el país on ha vingut a viure.

Per respondre a la varietat de necessitats formatives, d'horaris i de nivells, cal que l'oferta sigui encara més flexible, oberta $\mathrm{i}$ adient a les necessitats de cada usuari.

Finalment, cal que tothom assumeixi la fita de fer del català la llengua comuna. Amb independència de l'origen, amb independència de la llengua d'origen. Amb independència.

41 El detall de la seva programació és a http://www.gencat.cat/benestar/publica/butlletiI MMI/num18/documents/pluralitat_linguist.pdf 